\title{
Internal Fixation for Fracture of Femoral Head Associated A-Posterior Hip Dislocation: A Case Report
}

\author{
Rachid Ait Mouha, Ricardo Rosa Dasilva, Mwyniane Narcisse Dabire, Eric Bacheville, \\ Jean Hani Tawil
}

Orthopedics and Traumatology, Hospital of Orsay, Orsay, Essonne, France

Email: aitmouharachid@gmail.com

Received 22 June 2016; accepted 25 July 2016; published 29 July 2016

Copyright (C) 2016 by authors and OALib.

This work is licensed under the Creative Commons Attribution International License (CC BY).

http://creativecommons.org/licenses/by/4.0/

(c) (i) Open Access

\begin{abstract}
Fractures of the femoral head are rarely described. These fractures are diagnostic problems. The multiplicity of lesions associated with traumatic dislocations of the hip joint makes it difficult to establish a well-d therapeutic approach. A young biker suffers from dislocation of the hip fracture associated with a femoral head. Our approach was surgery. We use a Smith-Petersen exposure and the orthopedic table, useful for accessing and fixing fragment. There are many therapeutic options and depending on type of lesion, osteoarthritis is the most common complication.
\end{abstract}

\section{Keywords}

Femoral Head Fracture, Hip Dislocation, Hip Osteoarthritis, Internal Fixation

Subject Areas: Orthopedics

\section{Introduction}

Fractures of the femoral head are rarely described in lesions associated with hip dislocations [1]. These highenergy injuries are mostly associated with acetabular fracture from $6 \%$ to $15 \%$ [1]. These fractures are diagnostic problems. It is often not apparent on radiography as discussed by Richardson [2], as it poses an indication and treatment problem. Osteoarthritis of the hip remains the evolutionary complication of these lesions; few studies are interesting in the correlation between osteoarthritis of the hip and fracture of the femoral head.

\section{Case Report}

A young biker of 29 years old suffers of an accident of the public highway, the trauma was isolated with a direct impact point on the anterior surface of the left knee, emergency clinical examination of the left leg already fac-

How to cite this paper: Ait Mouha, R., Dasilva, R.R., Dabire, M.N., Bacheville, E. and Tawil, J.H. (2016) Internal Fixation for Fracture of Femoral Head Associated A-Posterior Hip Dislocation: A Case Report. Open Access Library Journal, 3: e2846. 
ing a traumatic luxation hip confirmed by pelvis radiography which showed a posterior dislocation of the hip fracture probably involve a femoral head (Figure 1), neurovascular complications were not found.

After reduction under general anesthesia, CT has helped to balance the lesion and Reveled a fractured lower third of the femoral head, precisely the lower anterior pole, several intra-articular fragments and no other injuries including acetabular (Figure 2(a), Figure 2(b)).

Our approach was surgery because the size of the fragment and reduction allow osteosynthesis, our choice of Smith-Petersen exposure and the orthopedic table facility was oriented mainly by the fracture site, this way allowed us easy access to the fracture and internal fixation with screws away like Herbert screw, the reduction was good (Figure 3). The postoperative result was simple, traction was set for 2 weeks and a discharge member for 3 months before support authorization.

After 7 years back, the patient has a normal functional activity of the hip, painless, and even a sport, the radiographs show no signs for osteoarthritis or head necrosis (Figure 3).

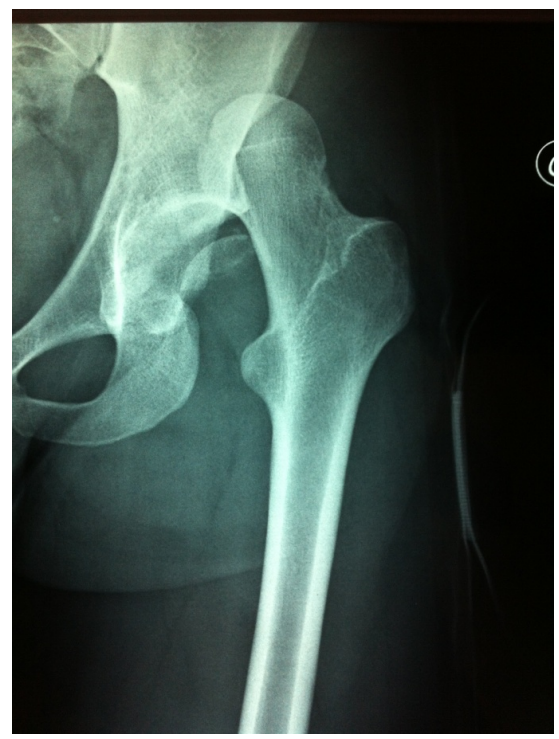

Figure 1. Pelvis radiography shows a posterior dislocation of the hip.

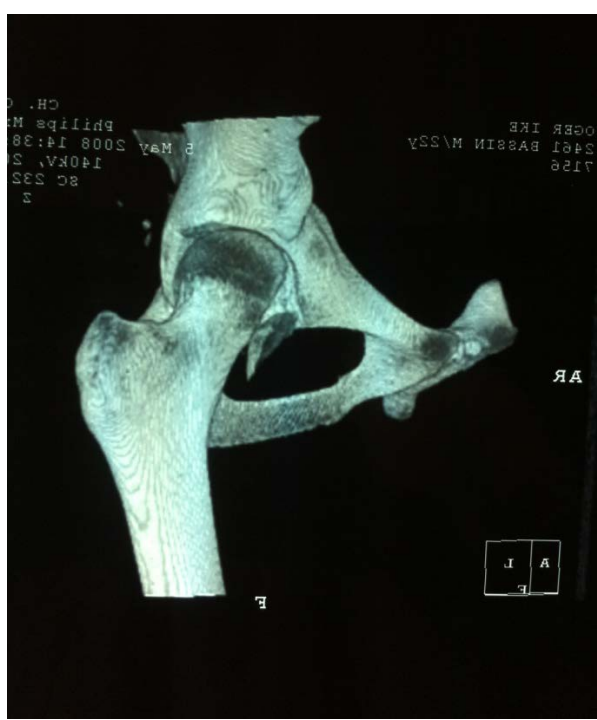

(a)

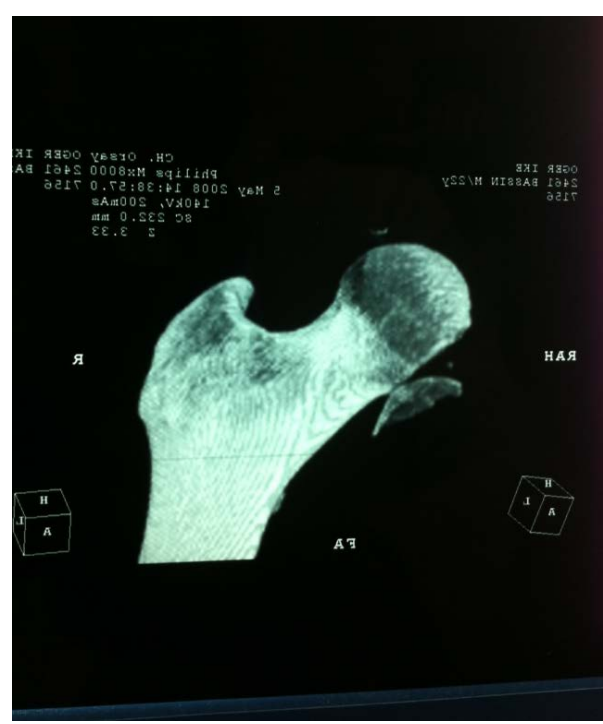

(b)

Figure 2. CT reveled a fractured lower third of the femoral head, of the lower anterior pole, several intra-articular fragments. 


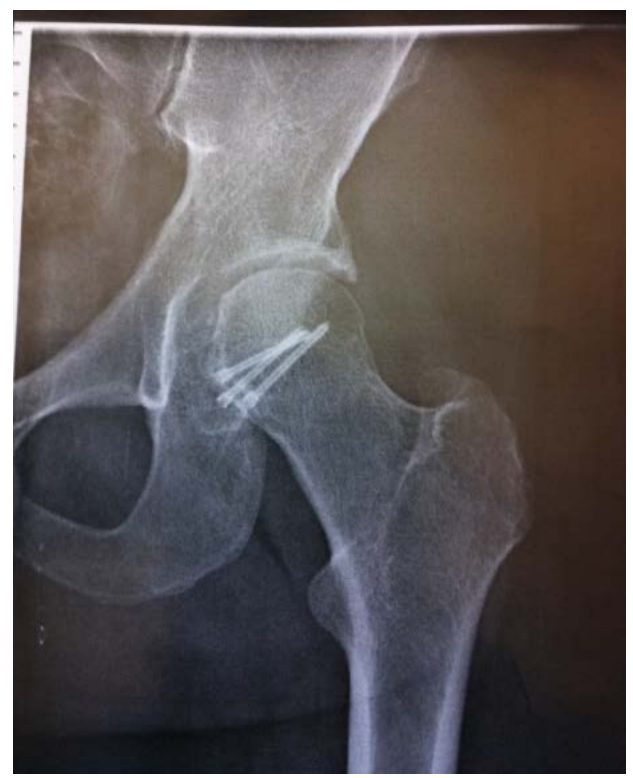

Figure 3. Radiography shows the reduction and internal fixation with screws away.

\section{Discussion}

The randomness of the mechanical force applied to the femur and the hip joint during high-energy trauma define the multiplicity of lesions associated with traumatic dislocations of this joint, acetabular fractures, femoral neck fracture and femoral head fracture or osteochondral are reported by Blankensteijn [3]. Fracture can be observed in all combinations, making it difficult to establish a well-defined therapeutic approach [1] [4], especially in case of fracture of the femoral head rarely associated.

The contribution of CT is not discussed in the diagnosis and analysis of these lesions [2], it is essential to define the therapeutic indication. Most studies were established before scanography be the norm. This is why it is difficult to find a classification wish brings the multitude change in lesion associate. So Pepkin classification, Yoon, and AO classification do not take the seat, the size of the fragment of the femoral head or osteochondral fractures into consideration. The recent classification of Chiron [1] is an alternative that includes varieties of fractures of the femoral head and the associated injuries.

The posterior surgical exposures are the most used approach (75\%) allows direct access to the posterior capsule especially in intractable posterior dislocations. The anterior exposures Hueter or Rottinger or Smith-Petersen (12\%) are useful for accessing and fixed the anterior inferior fragment and in case of fixing, our choice of the anterior Smith-Petersen exposure and the screw fixation was mainly depending of the site and size of the fragments, even if the capsular lesions was later. The medial approach described by Chiron seems logical for fixing anterior or internal fragment [5]. Arthroscopy is a relatively new and useful for removal of small fragments available [6]

Therapeutic options are many and depending on type of lesion, conservative treatment is still considered to reduced fracture 37.7\% as discussed elsewhere [4] [7] or removal or fixation depends on the size of the fragment, the osteosynthesis of the acetabulum and arthroplasty depending on the comminution of the fracture and associated fractures.

Osteoarthritis is the most common complication (43.7\%) [3] especially in acetabular fracture association, the management of time seems to be criminalized.

\section{Conclusion}

The fracture of the femoral head associated with posterior dislocation of the hip often goes unnoticed. Internal fixation seems to give good results when the fragment is accessible to osteosynthesis. The surgical approach for these lesions is rarely treated in literature. 


\section{References}

[1] Chiron, P., Lafontan, V. and Reina, N. (2013) Fracture-Dislocations of the Femoral Head. Orthopaedics \& Traumatology: Surgery \& Research, 99S, S53-S66. http://dx.doi.org/10.1016/j.otsr.2012.11.007

[2] Richardson, P., Young, J.W. and Porter, D. (1990) Ct Detection of Cortical Fracture of the Femoral Head Associated with Posterior Hip Dislocation. American Journal of Roentgenology, 155, 93-94. http://dx.doi.org/10.2214/ajr.155.1.2112874

[3] Blankensteijn, J.D., Lorie, C.A. and van der Werken, C. (1986) Traumatic Dislocation of the Hip with Fracture of the Femoral Head. Netherlands Journal of Surgery, 38, 121-124.

[4] Epstein, H.C., Wiss, D.A. and Cozen, L. (1985) Posterior Fracture Dislocation of the Hip (with Fractures of the Femoral Head. Clinical Orthopaedics and Related Research, 201, 91-97. http://dx.doi.org/10.1097/00003086-198512000-00002

[5] Chiron, P., Murgier, J., Cavaignac, E., Pailhé, R. and Reina, N. (2014) Minimally Invasive Medial Hip Approach. Orthopaedics \& Traumatology: Surgery \& Research, 100, 687-689. http://dx.doi.org/10.1016/j.otsr.2014.06.009

[6] Chernchujit, B., Sanguanjit, P., Arunakul, M., Jitapankul, C. and Waitayawinyu, T. (2009) Arthroscopic Loose Body Removal after Hip Fracture Dislocation: Experiences in 7 Cases. Journal of the Medical Association of Thailand, 92, S161-S164.

[7] Vielpeau, C., Lanoe, E., Hulet, C., Delbarre, J.C. and Tallier, E.B.L. (2001) Fracture-Dislocation of the Femoral Head: What Should Be Done with the Head Fragment? A Series of 32 Cases. Journal of Bone and Joint Surgery, 83B, 80-83.

\section{Submit or recommend next manuscript to OALib Journal and we will provide best service for you:}

- Publication frequency: Monthly

- 9 subject areas of science, technology and medicine

- Fair and rigorous peer-review system

- Fast publication process

- Article promotion in various social networking sites (LinkedIn, Facebook, Twitter, etc.)

- Maximum dissemination of your research work

Submit Your Paper Online: Click Here to Submit

Contact Us: service@oalib.com 